\title{
Effect of Recycling and Injection Parameters on Gloss Properties of Smooth Colored Polypropylene Parts: Contribution of Surface and Skin Layer
}

\author{
Souad Mbarek, ${ }^{1}$ Zaineb Baccouch $\mathbb{1}^{2},{ }^{2}$ Olivier Eterradossi, ${ }^{3}$ Didier Perrin, ${ }^{3}$ Bernard Monasse, ${ }^{4}$ Helene Garay, ${ }^{3}$ \\ Jean-Cristophe Quantin ${ }^{3}$ \\ ${ }^{1}$ Mechanical Department, Laboratoire de Mécanique de Sousse (LMS), LR11ES36, Université de Sousse, Sousse, \\ Tunisie \\ ${ }^{2}$ Mechanical Department, Laboratoire des Systèmes Electromécaniques (LASEM), LR 99ES36, Ecole Nationale \\ d'Ingénieurs de Sfax, Université de Sfax, Sfax, Tunisie \\ ${ }^{3}$ Matériaux Polymères Avancés, Centre des Matériaux des Mines d'Alès (C2MA), Ecole des mines d'Alès, Alès, France \\ ${ }^{4}$ Centre de Mise en Forme des Matériaux (CEMEF), Centre de Mise en Forme des Matériaux (CEMEF), Ecole des \\ mines de Paris, Paris, France
}

The aim of this article is to investigate the optical properties of a recycled polymer during numerous processes. The effects of different process parameters (number of grinding-injection cycles, material temperature, mold temperature, and injection rate) on gloss and color properties of a buff-colored polypropylene containing $2 \mathrm{wt} \% / \mathrm{wt}$ of pigment was considered. The variations of properties are in the same range that is observed by changing processing parameters. It is found that the roughness is not able to explicate the variation of the optical properties for these variations of conditions. In addition, the optical properties of the skin layer of the injected parts are associated with the observed gloss and color variations. Moreover, the change of spherulite dimensions is related with optical changes.

\section{INTRODUCTION}

The appearance properties of objects are one of the highest challenges of the present industries to keep a place in a highly competitive and highly diversified market. The requirement for the top quality appearance competes with the necessity of recycling, especially for the plastics industry evolving from a cradle-to-grave to a cradle-to-cradle life cycle of products. Plastics used to be recycled first to improve cost performance, but this recycling process is often per-ceived as bringing unfavorable effects, among which the decrease in appearance properties can be mentioned. To achieve this compromise between recycling and good aesthetics of products, the study of the effects of recycling on the appearance properties of polymers is needed. However, to the best of our knowledge, no study has been published about the effect of recycling on the appearance properties of injected parts, while the analysis of the effect of recycling on the optical properties of polymer films is still scarce in the literature [1, 2]. Among other plastics, polypropylene (PP) is a commodity poly-mer used in large quantities for many applications. The main reasons for the success of PP are quite good price/performance ratio, excel-lent mechanical properties, and suitable optical characteristics [3].

Correspondence to: Z. Baccouch; e-mail: baccouch.zaineb@gmail.com
The huge consumption of this polymer makes its recycling strategically very important for the environmental policy of industry [4].

The effects of recycling on optical properties have been marginally analyzed in literature [1]. The optical transparency in semicrystalline polymers is mainly related to crystallinity and to surface properties [5]. It has been found that the haze of polyethylene (PE) blown films is primarily caused by the scattering of light due to surface irregularities [6]. Surface scattering is one of the major reasons for the loss of optical transparency [7]. Nonetheless, optical transparency is also lowered because the scattering takes place when light passes through boundaries between the domains of different refractive indices, for example, between amorphous and crystalline domains in polymers. Spherulites in PP are much larger than the wavelength of visible light $(0.4-0.7 \mu \mathrm{m})$, and the refractive index of crystalline regions is higher than that of amorphous regions. Due to their noncrystalline structure, amorphous materials have better optical transparency than semicrystalline materials, and a decrease in crystallinity of a semicrystalline polymer enhances its clarity [8].

On the other hand, the appearance properties of molded polymer products are mostly determined by the injection process parameters. The low surface temperature of the cavity, for example, makes the polymer melt freeze prematurely, and consequently a frozen layer (skin) will form at the interface between the hot polymer melt and the cold mold cavity during the filling phase. Thus, the combined actions of processing parameters, polymer formulation, and mold geometry lead to a set of appearance defects observed on the surface of the resulting molded parts. The main defects are flow marks $[9,10]$, weld lines [11, 12], swirl marks [13-15], roughness [16, 17], low gloss $[18,19]$, and a low replication accuracy [20, 21]. Zhang et al. [22] shown that the mean surface quality of plastic parts can be significantly improved by increasing the mold cavity temperature. The gloss of both ABS/PMMA and ABS/PMMA/nano- $\mathrm{CaCO}_{3}$ gradually increases with the increase of mold cavity temperature. Process conditions were shown to have a strong influence not only on gloss development, but also on the color of pigmented PP [18]. A better replication of the mold texture can be achieved at a lower melt viscosity for higher shear rates and higher mold temperatures, giving higher gloss in smooth regions. Gloss was mentioned to have a significant effect on color: all the factors that contribute to an increase in gloss show concomitant effects of increasing color coordinate $b^{*}$ and of decreasing lightness $L^{*}$ [18]. However, this is probably not a material-related issue, but a classical colorimetric one due not only to 
the psychophysics of color perception, but also to the standard methodologies of colorimetric measurements. A great deal of research work has proven that the processing parameters may affect the gloss of parts molded by injection on a mirror-polished surface [23-26]. The mold temperature is commonly considered as the most important parameter to be controlled, as it was clearly shown that it is highly relevant and clearly interactive with the holding pressure [19].

From a physical point of view, the two relevant psychophysical dimensions of appearance (gloss and color) are the perceptual consequences of the light-matter interaction at the surface of an opaque sample. Gloss is related to the amount of light reflected in the specular direction and depends only on surface properties, while color arises from diffusion and absorption processes taking place under the surface $[27,28]$. The four variables that primarily affect gloss are the wavelength and incidence angle of light [29], the refractive index of the material [28, 30], and surface topography (or texture) [31]. Moreover, contrast gloss [32] describes the influence of the overall color on the perceived gloss (for constant reflected intensities in the specular direction, gloss is perceived as being higher on darker backgrounds). Color itself depends on the illumination conditions, observation angle, optical characteristics of the material, amount of pigments, surface topography [32], and gloss [33, 34]. Many research works on polymeric surfaces classically have shown a decrease in gloss with the increase in roughness [35].

This article is interested in the effects of the number of grinding-injection cycles and three process parameters (material temperature $\left(\boldsymbol{T}_{\text {mat }}\right)$, mold temperature $\left(\boldsymbol{T}_{\text {mold }}\right)$, and injection rate (Inj rate) on gloss and color properties of a buff-colored polypropylene containing $2 \mathrm{wt} \% / \mathrm{wt}$ of pigment. The study was aimed at finding how many recycling's are possible while maintaining good optical properties and which are the most favorable parameters to achieve this goal. The main contribution is to show the direct relationship between appearance (gloss and color) modifications and the semicrystalline morphology in the skin layer.

\section{EFFECT OF RECYCLING AND INJECTION PARAMETERS ON OPTICAL PROPERTIES OF INJECTED PARTS: GLOSS AND COLOR}

The material selected for this study was a polypropylene because of its large use and the growing demand for recycling. The PP material was formulated from a color master batch. The first injections were done under different processing parameters and some of these injected parts were ground and injected again up to five times. The effect of recycling and that of processing parameters on both gloss and color of a mirror-finished surface were investigated. Such a surface finish highlights gloss variations, and therefore is the extreme condition to check the effect either of recycling or of processing conditions.

\section{Materials and Experimental Methods}

Polymer Processing. The PP homopolymer SABIC ${ }^{\circledR}$ PP 575P produced by SABIC Europe was used in the experiments. It is a homopolymer recommended for injection molding (MFI 10.5 at $230^{\circ} \mathrm{C}$ and $2.16 \mathrm{~kg}$, molecular weight). A masterbatch supplied by Clariant was used to obtain a gray-beige complexion. Color originates in mineral phases only, with a common formulation for such a buff-color masterbatch. The blending of PP with $2 \mathrm{wt} \% / \mathrm{wt}$ of pigments (masterbatch or pigments) was performed at Innovation Plasturgie Composites-Technical center of plasturgy and Composites (PEP, Bellignat, France), using a co-rotating intermeshing twin-screw extruder (Clextral EVOLUM HT 32, diameter $32 \mathrm{~mm}$, centerline distance $21 \mathrm{~mm}$ ) with a length to diameter ratio L/D of 44. The screw profile is made up of conveying and kneading elements, as well as using opposite pitch to ensure melting, mixing, shearing, and a good dispersion of the components. The extrusion process was carried out with a screw rotation speed of $350 \mathrm{rpm}$, at a temperature of $210^{\circ} \mathrm{C}$ and a $30 \mathrm{~kg} \cdot \mathrm{h}^{-1}$ throughput. The raw-colored pellets from the masterbatch were also injection-molded to obtain samples used in additional characterization tasks.

The mold (design: C2MA, IMT Mines Alès; supplier: CFO Outillage, Anduze, France) is $346 \times 296 \times 204 \mathrm{~mm}^{3}$ with a cavity of $100 \times 100 \times 2 \mathrm{~mm}^{3}$. The upper and lower surfaces are parallel, one being flat and mirror-polished, and the other grained $(20 \mu \mathrm{m}$ chemical graining). Only the mirror-polished surface is considered in this article.

All specimens were injected at C2MA (Ecole des mines d'Alès, Alès, France) on a Krauss Maffei KM50-180CX injection molding machine (maximum clamping force 50 tons, screw diameter $28 \mathrm{~mm}$ ). During the experiments, the first five samples of each injection run were discarded to ensure a stable process. After the random sampling of the injected parts to be studied, the remaining parts were ground using a Cutting Mill SM 300 (Retsch, France) before being injected again. The cycle was repeated up to 5 times.

Experimental Design. A specific experimental design applied to the number of injection cycles and three injection parameters (injection and mold temperature, injection rate) was used to limit the cost and duration of the experimental phase. The choice was made of an asymmetrical screening design $3^{3} 1^{5} / / 18$ [36, 37], each experiment being repeated three times. This allowed the investigation of four factors in 18 experiments, with the three process factors at three levels and the fourth (cycle) at five levels. Table 1 lists the values given to each factor. Furthermore, three runs in the center of the domain of experiments (DOE), that is, $240^{\circ} \mathrm{C}$, $50^{\circ} \mathrm{C}$, and $20^{\circ} \mathrm{C}$, and five $t$-tests were added by cycle in order to improve statistical evaluation and to validate the estimated model, respectively. Hence, 45 runs were obtained from the initial design. Table 2 shows the experimental parameters and corresponding name of the subset of samples used in this paper.

This design was generated and analyzed with the statistical software NEMRODW ${ }^{\circledR} 2015$ using the least square method $[36,37]$ on all 45 runs.

TABLE 1. Experimental conditions of the asymmetrical screening design.

\begin{tabular}{lcccc}
\hline \multicolumn{5}{c}{ Factors } \\
\cline { 2 - 5 } Levels & $\mathrm{T}$ injection $\left({ }^{\circ} \mathrm{C}\right)$ & $\mathrm{T}$ molding $\left({ }^{\circ} \mathrm{C}\right)$ & Injection rate $\left(\mathrm{cm}^{3} / \mathrm{s}\right)$ & Cycle \\
\hline 1 & 220 & 30 & 10 & Cycle 0 \\
2 & 240 & 50 & 20 & Cycle 1 \\
3 & 260 & 80 & 40 & Cycle 2 \\
4 & - & - & - & Cycle 3 \\
5 & - & - & - & Cycle 4 \\
\hline
\end{tabular}


TABLE 2. Reduced samples set with corresponding injection parameters and cycles.

\begin{tabular}{lcccc}
\hline $\begin{array}{l}\text { Sample } \\
\text { reference }\end{array}$ & $\begin{array}{c}\text { Injection } \\
\text { temperature }\left({ }^{\circ} \mathrm{C}\right)\end{array}$ & $\begin{array}{c}\text { Molding } \\
\text { temperature }\left({ }^{\circ} \mathrm{C}\right)\end{array}$ & $\begin{array}{c}\text { Injection rate } \\
\left(\mathrm{cm}^{3} / \mathrm{s}\right)\end{array}$ & Cycle \\
\hline PPN1 & 220 & 30 & 10 & Cycle 0 \\
PPN5 & 220 & 80 & 40 & Cycle 0 \\
PPN10 & 220 & 80 & 10 & Cycle 1 \\
PPN27 & 260 & 80 & 20 & Cycle 3 \\
PPN44 & 220 & 80 & 20 & Cycle 3 \\
PPN7 & 240 & 50 & 20 & Cycle 0 \\
PPN39 & 240 & 50 & 20 & Cycle 4 \\
PPN13 & 260 & 80 & 40 & Cycle 1 \\
PPN6 & 240 & 50 & 20 & Cycle 0 \\
PPN38 & 240 & 50 & 20 & Cycle 4 \\
\hline
\end{tabular}

Appearance Measurements. Three randomly selected parts were characterized for each of the 45 injection runs, taking 4 measurements on each part.

Color coordinates were measured using a Datacolor CS-3 spectrocolorimeter with standard $\mathrm{d} / 8^{\circ}$ geometry, set in the "specular excluded" (SCE) configuration. The instrument has a repeatability better than 0.01 RMS $\Delta \mathrm{E}$. Coordinates are given for CIELab color space, with D65 illuminant and $10^{\circ}$ observer.

Gloss was measured in the traditional industrial way using a Dr LANGE LMG-064 glossmeter compliant with the DIN 67530 standard. It is given in conventional gloss units (GU), the standard being a black Carrara flat glass (refractive index 1.567) with gloss values of 88,93 , and 99 UB at measurement angles of 20,60, and $85^{\circ}$, respectively. The additional measurements of contrast gloss, not reported here, were performed using a goniometric spectrophotometer.

Data analysis was carried out to obtain an empirical screening model defining the responses of the reflectometer readings (R20, R60, and R85) accounting for gloss and those of the CIE Lab color coordinates $\left(\mathrm{L}^{*}, \mathrm{a}^{*}\right.$, and $\left.\mathrm{b}^{*}\right)$ accounting for color.

Atomic Force Microscopy. AFM was used to study the surface topography of the injected samples. Measurements were carried out at room temperature in tapping mode using a 5,500-LS instrument from Agilent Technologies with a frequency of $54 \mathrm{KHz}$. The scan size was set to $50 \mu \mathrm{m} \times 50 \mu \mathrm{m}$ with a lateral resolution of $97 \mathrm{~nm} /$ point.

Optical Microscopy. The optical microscopy analysis was conducted with a Leica DMRX microscope under natural, nonpolarized light with a large aperture lens ( 440 , angle $\left.45^{\circ}\right)$. Using the z-stacking (multi plan focus) capability of the microscope, pictures were obtained at different depths under the sample surface, and corrected for refraction (using the Snell-Descartes law of refraction). Illumination and camera settings were kept constant for all samples. Both lateral and depth resolution were $0.5 \mu \mathrm{m}$. The microscope was coupled with a digital camera in the linear mode. Images with slightly homogeneous illumination (deviation from homogeneity $\sim 10 \%$ ) were processed to correct for light in homogeneity and intensity of dark and bright grains from the mean value. The treatment of intensity distribution as a function of depth and the statistical analysis with the software Image J allow us to define the penetration depth of the light, producing a significant contribution on the backscattered light. The area of the MEB photo was binarized.

X-Ray Diffraction. X-ray diffraction measurements were performed on an X-ray Diffractometers Scientific ARL EQUINOX 1000 powder diffractometer, provided with a $\mathrm{Cu} \mathrm{K}$ emission tube. Measurements were taken from $2^{\circ}$ to $100^{\circ} 2 \theta$ at an average scanning rate of $0.2-0.6^{\circ} \%$.

IR Analysis. IR-ATR spectra were recorded on an IRTF IS10. The apparatus was equipped with the sampling compartment with a variable angle internal reflection system using a KRS-5 crystal. The infrared measurements were performed using a ThermoOptek interferometer (type 6,700) equipped with a global source and $\mathrm{KBr} / \mathrm{Ge}$ beamsplitters coupled to an Infrared microscope (NicPlan, Nicolet) equipped with an MCT (Mercury Cadmium Telluride) detector in order to investigate the spectral range $\left(400-7,500 \mathrm{~cm}-{ }^{1}\right)$.

\section{RESULTS}

Gloss and Color Measurements. In this section, the effect of recycling and injection parameters on the variation of colorimetric

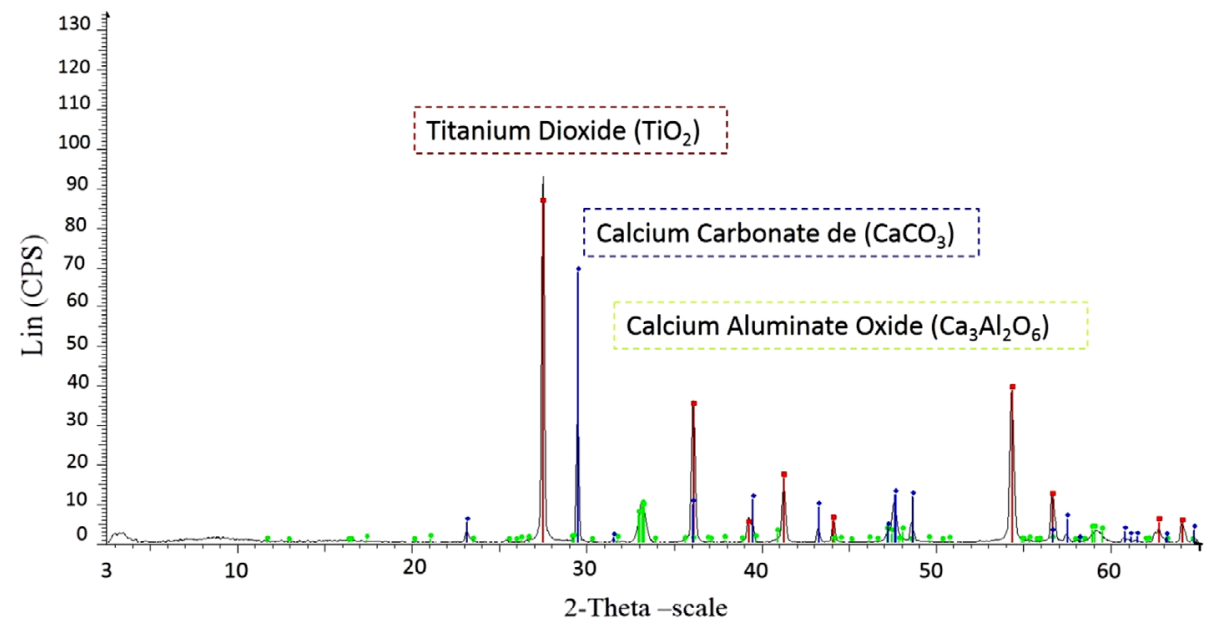

FIG. 1. XRD patterns of masterbach put in an oven at $650^{\circ} \mathrm{C}$. [Color figure can be viewed at wileyonlinelibrary.com] 


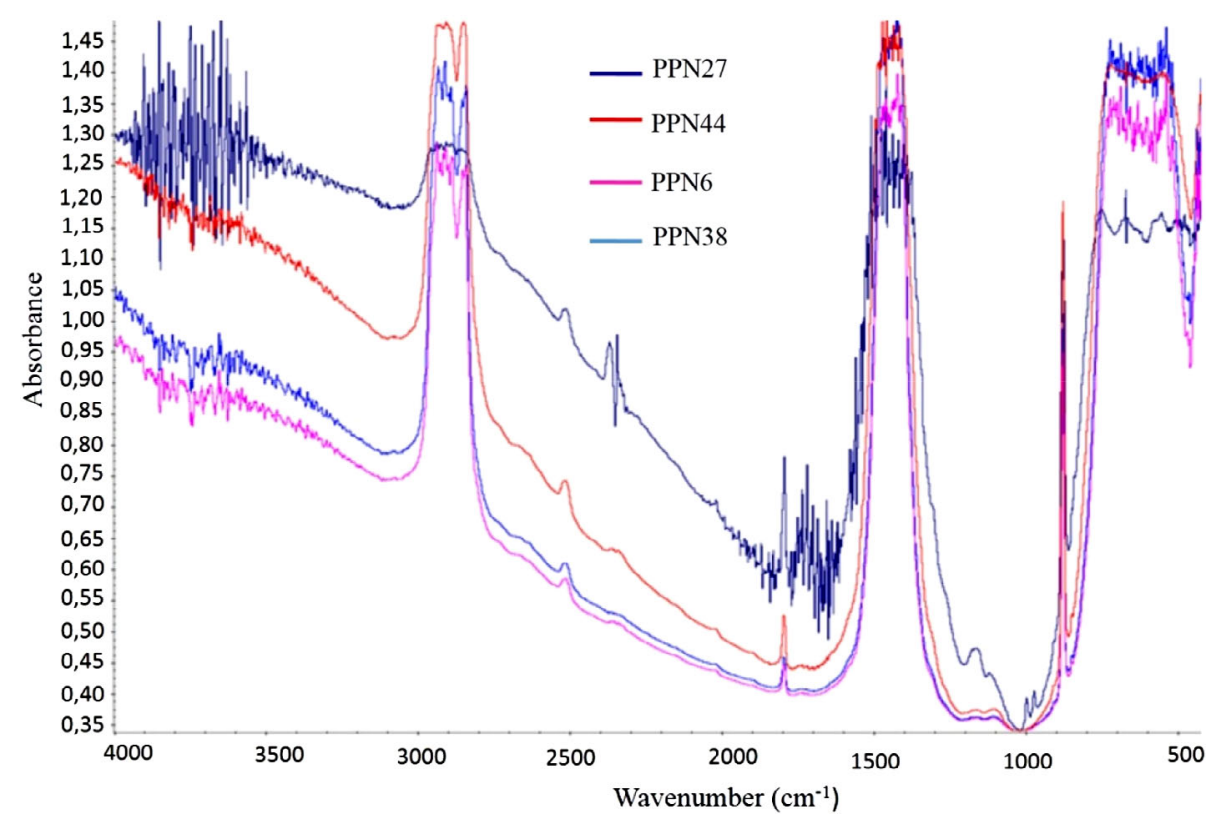

FIG. 2. IR spectra of PP plus masterbach extracted from samples. PPN27 $\left(T_{\text {mat }}=260^{\circ} \mathrm{C}, T_{\text {mold }}=80^{\circ} \mathrm{C}\right.$, Inj $\left._{\mathrm{rate}}=20 \mathrm{~cm}^{3} / \mathrm{s}\right)$, PPN44 ( $\left.T_{\text {mat }}=220, T_{\text {mold }}=80^{\circ} \mathrm{C}, I_{\text {rate }}=20 \mathrm{~cm}^{3} / \mathrm{s}\right)$, PPN6 $\left(T_{\text {mat }}=240^{\circ} \mathrm{C}, T_{\text {mold }}=50^{\circ} \mathrm{C}, I_{j_{\text {rate }}}=20 \mathrm{~cm}^{3} / \mathrm{s}\right)$, and PPN38 $\left(T_{\text {mat }}=240^{\circ} \mathrm{C}, T_{\text {mold }}=50^{\circ} \mathrm{C}, \operatorname{Inj}_{\text {rate }}=20 \mathrm{~cm}^{3} / \mathrm{s}\right.$ ). [Color figure can be viewed at wileyonlinelibrary.com]

TABLE 3. Gloss properties (R20, R60, and R85) and color coordinates (L*, a*, and b*).

\begin{tabular}{|c|c|c|c|c|c|c|}
\hline \multirow[b]{2}{*}{ Sample } & \multicolumn{3}{|c|}{ Gloss (in gloss units, GU) } & \multicolumn{3}{|c|}{ Color coordinates (CIELab, D65, $10^{\circ}$ observer) } \\
\hline & $\mathrm{R} 20$ & R60 & $\mathrm{R} 85$ & $\mathrm{~L}^{*}$ & $a^{*}$ & $\mathrm{~b}^{*}$ \\
\hline PPN1 & 77.0 & 85.9 & 101.0 & 47.2 & 0.95 & 6.12 \\
\hline PPN5 & 77.4 & 88.6 & 101.5 & 47.0 & 0.94 & 5.98 \\
\hline PPN10 & 76.7 & 88.3 & 101.8 & 49.1 & 0.95 & 5.88 \\
\hline PPN27 & 73.0 & 90.0 & 107.1 & 50.2 & 1.07 & 6.70 \\
\hline PPN44 & 76.5 & 91.0 & 107.0 & 49.3 & 0.97 & 6.0 \\
\hline PPN7 & 76.7 & 87.8 & 100.2 & 48.7 & 0.94 & 5.65 \\
\hline PPN39 & 75.9 & 89.5 & 104.2 & 49.7 & 0.97 & 6.42 \\
\hline PPN13 & 73.3 & 89.1 & 102.7 & 49.4 & 1.00 & 6.20 \\
\hline PPN6 & 76.0 & 87.7 & 99.8 & 48.8 & 0.94 & 5.66 \\
\hline PPN38 & 75.7 & 88.6 & 104.4 & 49.7 & 0.97 & 6.41 \\
\hline 476 samples (mean) & 75.7 & 88.9 & 103.2 & 49.3 & 0.99 & 6.24 \\
\hline 476 samples (median) & 76.0 & 88.9 & 103.3 & 49.4 & 0.99 & 6.24 \\
\hline
\end{tabular}

and gloss properties of samples will be highlighted. In order to study the color of the material, a colorant (masterbatch) was added and extruded with the PP matrix before the injection.

Firstly, a study of the stability of the masterbatch was conducted, taking into consideration the colorant by XRD Diffraction.
In fact, the masterbatch was put in an oven at $650^{\circ} \mathrm{C}$ for different times. After that, the obtained powder was analyzed by XRD Diffraction. The patterns show that we have a mineral dye composed of: Titanium of Dioxide $\mathrm{TiO}_{2}$, tricalcium Aluminate $\mathrm{Ca}_{3} \mathrm{Al}_{2} \mathrm{O}_{6}$ and calcium carbonate $\mathrm{CaCO}_{3}$ (Fig. 1).

TABLE 4. Roughness (Ra) and gloss properties (R20, R60, and R85) for injected polypropylene samples.

\begin{tabular}{lcrr}
\hline Sample & Ra $(\mathrm{nm})$ & $\mathrm{R} 20$ & $\mathrm{R} 60$ \\
\hline PPN5 $\left(T_{\text {mat }}=220^{\circ} \mathrm{C}, T_{\text {mold }}=80^{\circ} \mathrm{C}\right.$, Inj $\left._{\text {rate }}=40 \mathrm{~cm}^{3} / \mathrm{s}\right)$ & 10,49 & $77,5 \pm 1,50$ & $88,5 \pm 2,35$ \\
PPN10 $\left(T_{\text {mat }}=220^{\circ} \mathrm{C}, T_{\text {mold }}=80^{\circ} \mathrm{C}\right.$, Inj $\left._{\text {rate }}=10 \mathrm{~cm}^{3} / \mathrm{s}\right)$ & 10,20 & $76,5 \pm 0,70$ & $88 \pm 0,90$ \\
PPN27 $\left(T_{\text {mat }}=260^{\circ} \mathrm{C}, T_{\text {mold }}=80^{\circ} \mathrm{C}\right.$, Inj $\left._{\text {rate }}=20 \mathrm{~cm}^{3} / \mathrm{s}\right)$ & 18,40 & $73 \pm 1,00$ & $101,5 \pm 0,9$ \\
PPN44 $\left(T_{\text {mat }}=220^{\circ} \mathrm{C}, T_{\text {mold }}=80^{\circ} \mathrm{C}\right.$, Inj $\left._{\text {rate }}=20 \mathrm{~cm}^{3} / \mathrm{s}\right)$ & 8,84 & $76,5 \pm 1,30$ & $102 \pm 2,00$ \\
PPN7 $\left(T_{\text {mat }}=240^{\circ} \mathrm{C}, T_{\text {mold }}=50^{\circ} \mathrm{C}\right.$, Inj $\left._{\text {rate }}=20 \mathrm{~cm}^{3} / \mathrm{s}\right)$ & - & $76,5 \pm 0,86$ & $91 \pm 1,55$ \\
PPN39 $\left(T_{\text {mat }}=240^{\circ} \mathrm{C}, T_{\text {mold }}=50^{\circ} \mathrm{C}\right.$, Inj $\left._{\text {rate }}=20 \mathrm{~cm}^{3} / \mathrm{s}\right)$ & - & $76 \pm 1,20$ & $88 \pm 0,83$ \\
PPN13 $T_{\text {mat }}=\left(260^{\circ} \mathrm{C}, T_{\text {mold }}=80^{\circ} \mathrm{C}\right.$, Inj $\left._{\text {rate }}=40 \mathrm{~cm}^{3} / \mathrm{s}\right)$ & & $73 \pm 0,48$ & $89,5 \pm 0,90$ \\
\hline
\end{tabular}


(a)

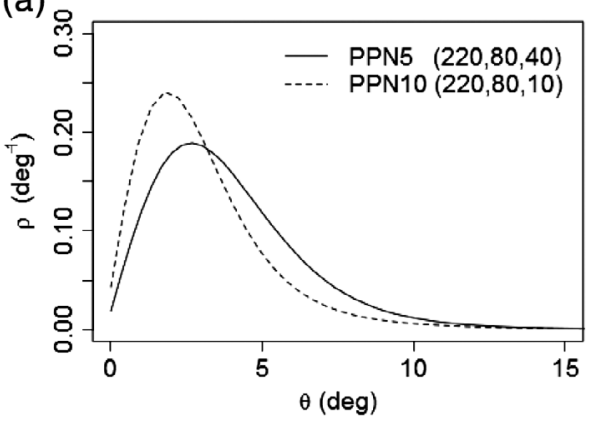

(b)

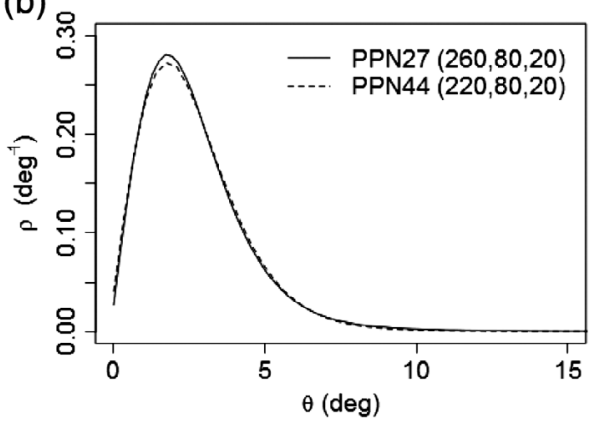

FIG.3 Probability density functions of slopes, computed from AFM measurements.

Moreover, the Infrared analysis of different films cut from the samples (PP plus Masterbatch) demonstrate the stability of the masterbatch after many injecting cycles with different parameters. In fact, Fig. 2 shows that the same peaks exist for all analyzed polymers. Consequently, the injection parameters either the number of cycles does not affect the structure of the polymer with the masterbach.

Based on the results obtained in this study, we can confirm that the variation of the colorimetric and gloss in the samples depends
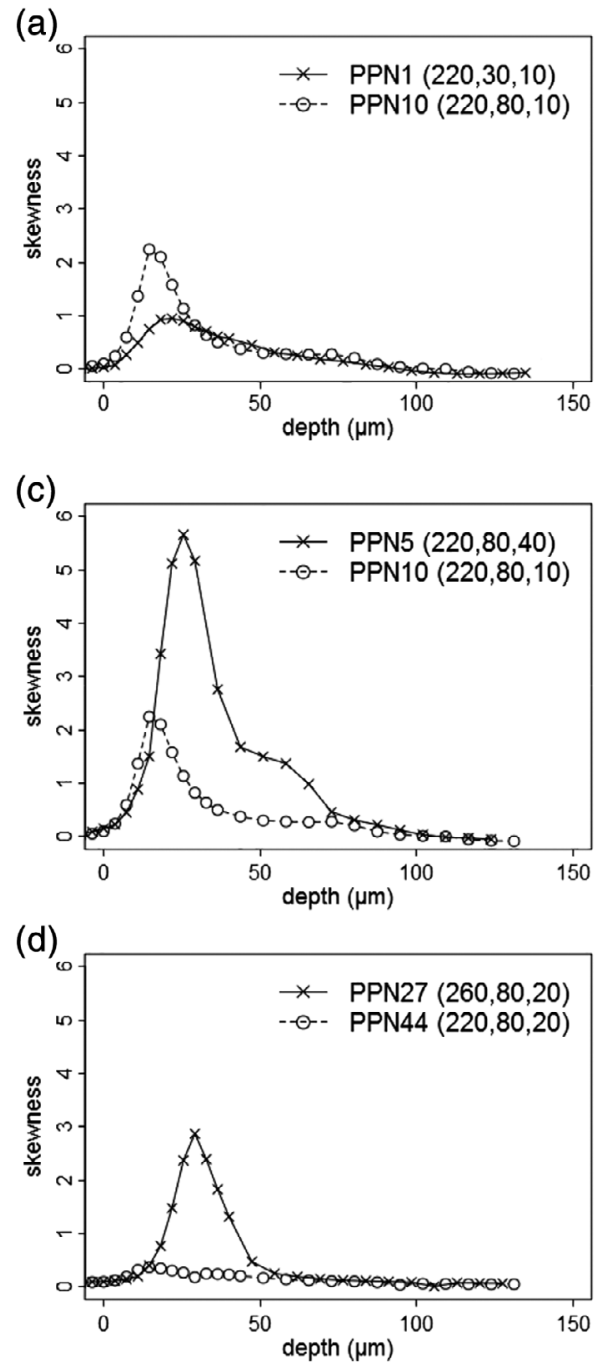

only on the injecting parameters (Temperature of material $\left(T_{\text {mat }}\right)$, temperature of mold $\left(T_{\text {mold }}\right)$, Injection rate $\left.\left(\operatorname{Inj}_{\text {rate }}\right)\right)$.

The results for the selected subset of samples are given in Table 3 together with the means and medians of the whole experimental design.

R20 and R60 gloss values are in accordance with those of a glossy material $(\mathrm{R} 60>70 \mathrm{UB})$, for which the standard requires the use of R20 as a characteristic. Moreover, the couple of values
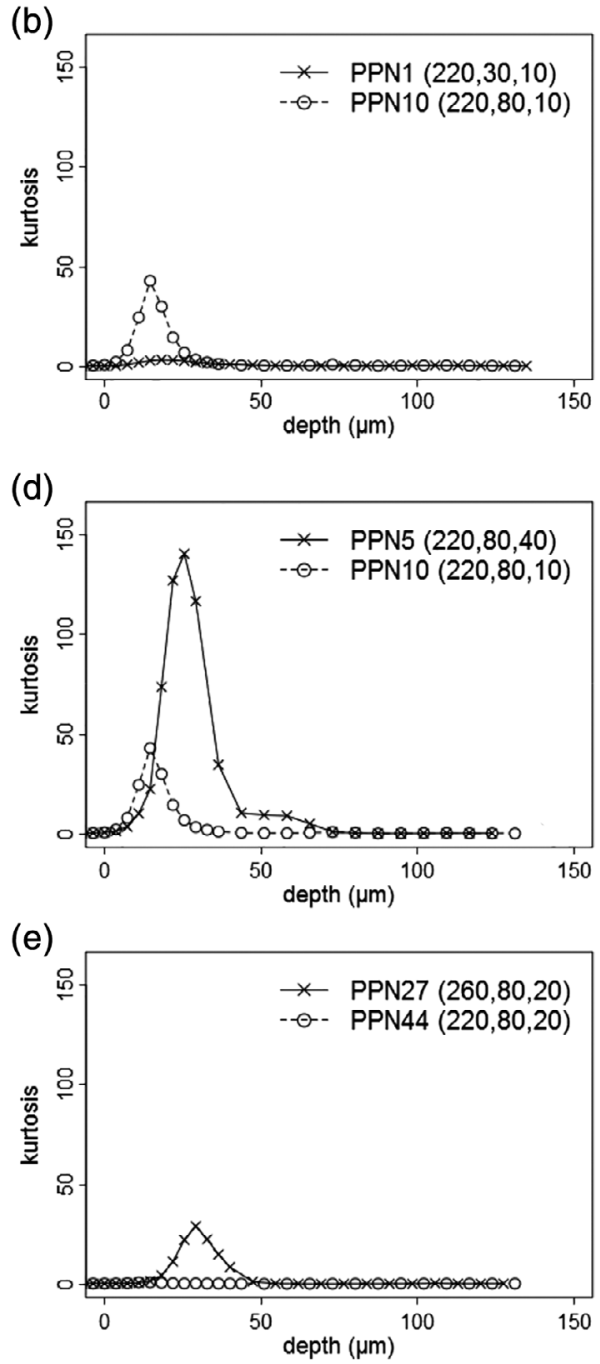

FIG. 4. Distribution of backscattered intensity in microscopic observations images, skewness (a, c, e), and kurtosis (b, d, f) versus depth for different samples. 

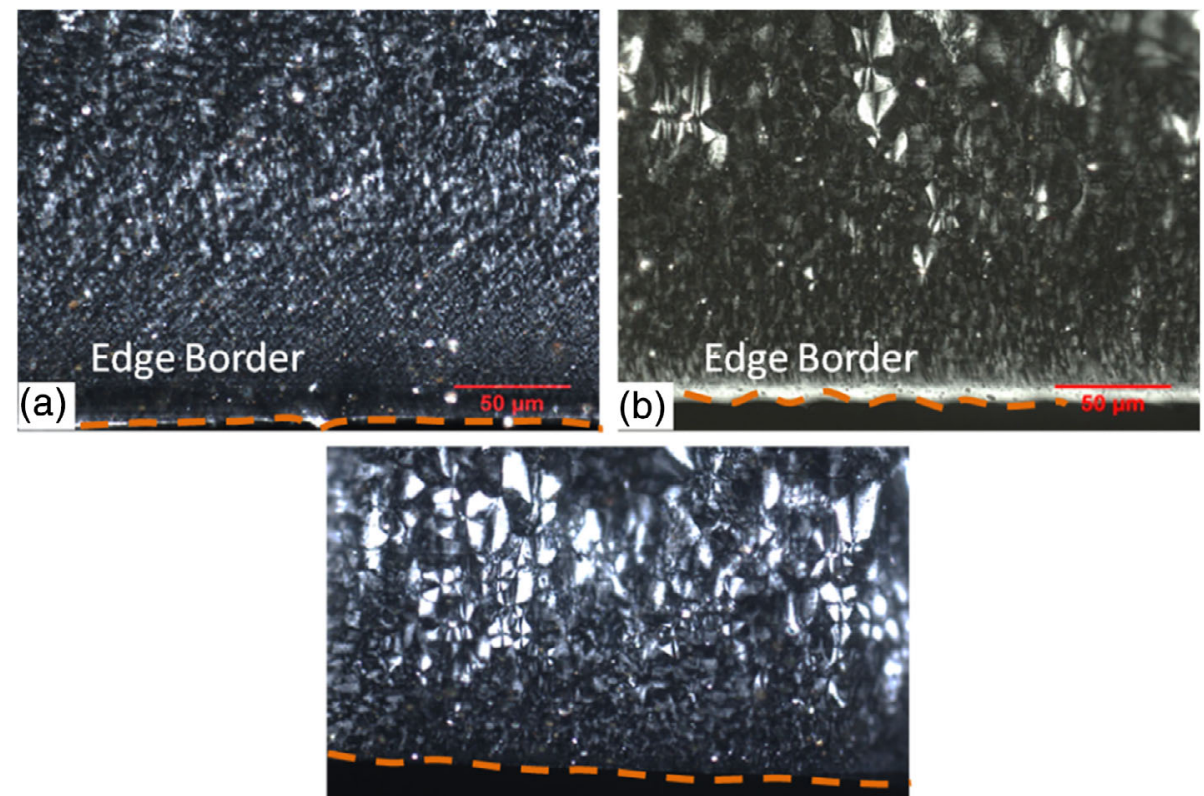

(c) Edge Border

FIG. 5. Micrographs obtained from transmitted, polarized light optical microscopy. (a) PPN1 $\left(T_{\text {mat }}=220^{\circ} \mathrm{C}\right.$, $T_{\text {mold }}=30^{\circ} \mathrm{C}$, Inj $\left._{\text {rate }}=10 \mathrm{~cm}^{3} / \mathrm{s}\right)$, (b) PPN10 $\left(T_{\text {mat }}=220^{\circ} \mathrm{C}, T_{\text {mold }}=80^{\circ} \mathrm{C}\right.$, Inj $\left._{\text {rate }}=10 \mathrm{~cm}^{3} / \mathrm{s}\right)$, (c) PPN5 $\left(T_{\text {mat }}=220^{\circ} \mathrm{C}\right.$, $T_{\text {mold }}=80^{\circ} \mathrm{C}$, Inj rate $_{\text {re }}=40 \mathrm{~cm}^{3} / \mathrm{s}$ ). [Color figure can be viewed at wileyonlinelibrary.com]

agree well with a refractive index that is slightly smaller than 1.5 and an imaginary (absorption) part close to 0.2. However, some of the R85 values are too high for a material with such optical characteristics; they are not expected to range over $102 \mathrm{GU}$ and this most probably indicates that some of the samples are not flat but undergo surface deformation due to the processing conditions. This was confirmed using a goniometric spectrophotometer.

Experimental Design Analysis. From the analysis, it is clearly identified that gloss responses R20, R60 and R85 are mainly

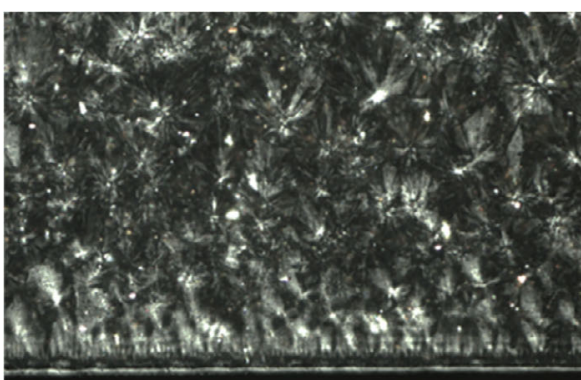

(a)

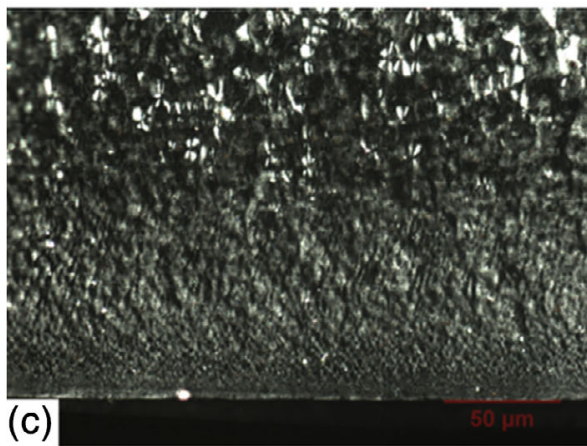

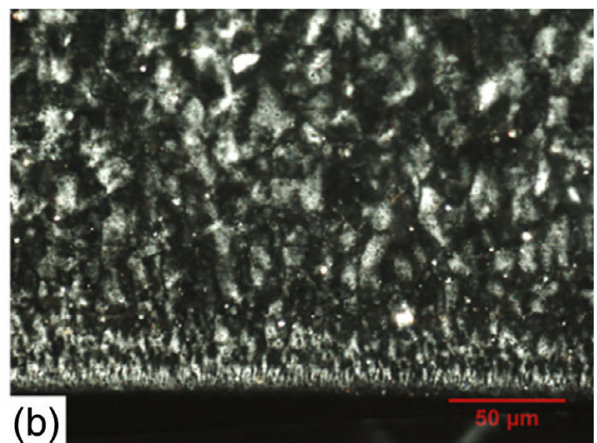

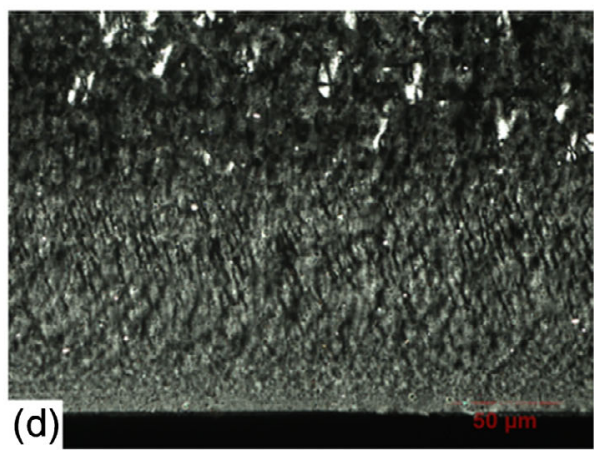

FIG. 6. Micrographs obtained from polarized light optical microscopy in transmission. (a) $\mathrm{PPN} 27\left(T_{\mathrm{mat}}=260^{\circ} \mathrm{C}\right.$, $T_{\text {mold }}=80^{\circ} \mathrm{C}$, Inj $\left._{\text {rate }}=20 \mathrm{~cm}^{3} / \mathrm{s}\right)$, (b) PPN44 $\left(T_{\text {mat }}=220, T_{\text {mold }}=80^{\circ} \mathrm{C}\right.$, Inj $\left._{\text {rate }}=20 \mathrm{~cm}^{3} / \mathrm{s}\right),(\mathrm{c})$ PPN6 $\left(T_{\text {mat }}=240^{\circ} \mathrm{C}\right.$, $\left.T_{\text {mold }}=50^{\circ} \mathrm{C}, \operatorname{Inj}_{\text {rate }}=20 \mathrm{~cm}^{3} / \mathrm{s}\right)$, (d) PPN38 $\left(T_{\text {mat }}=240^{\circ} \mathrm{C}, T_{\text {mold }}=50^{\circ} \mathrm{C}, \mathrm{Inj}_{\text {rate }}=20 \mathrm{~cm}^{3} / \mathrm{s}\right)$. [Color figure can be viewed at wileyonlinelibrary.com] 

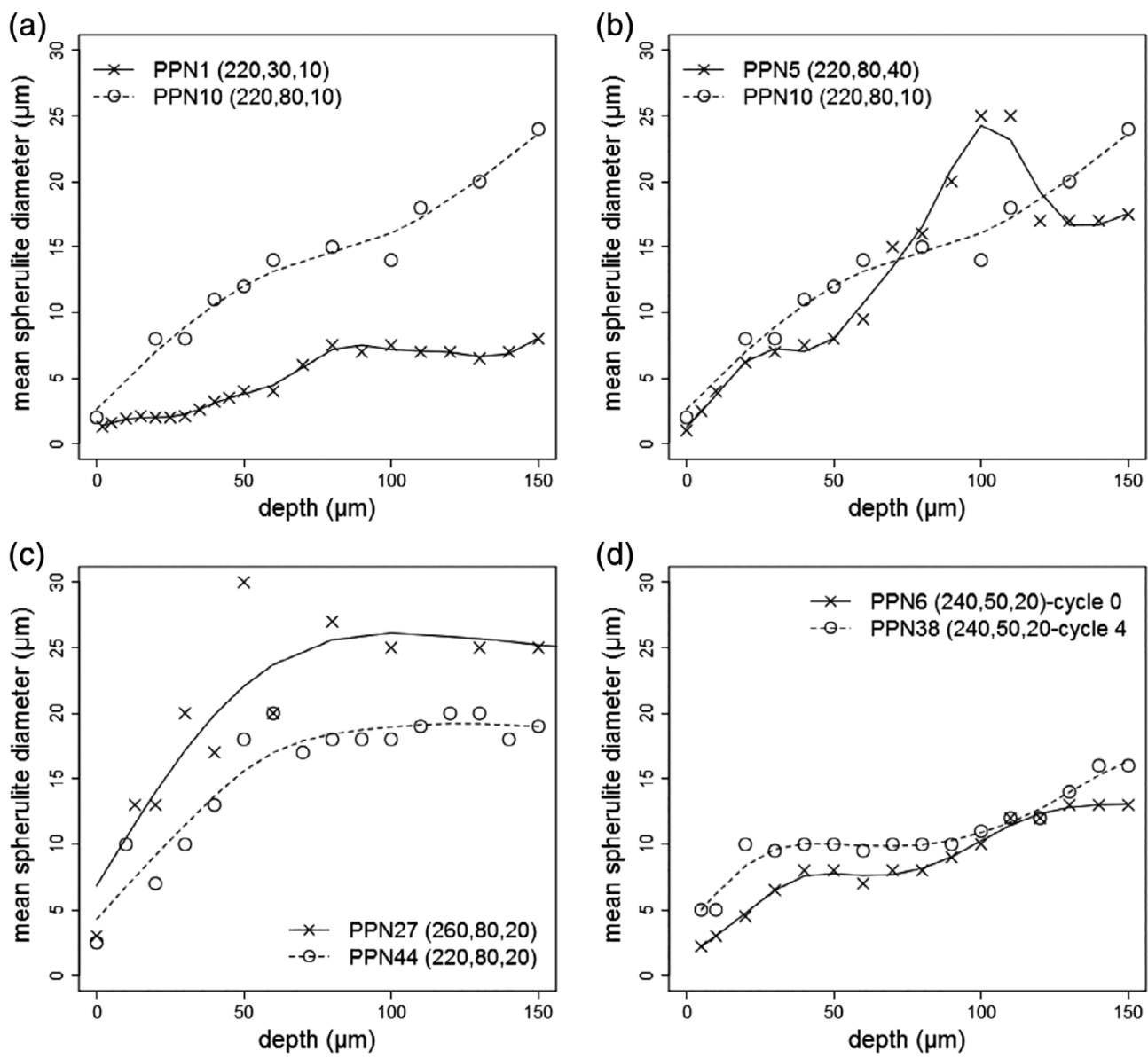

FIG. 7. Average spherulites diameter versus distance from the surface of sample, for samples of Fig. 2. Solid and dotted lines provided as eye guides (using a smoothing spline approximation).

influenced by Cycle and Molding Temperature factors, while Cycle and Injection Temperature parameters have major influence on color responses ( $\mathrm{L}^{*}, \mathrm{a}^{*}$, and $\left.\mathrm{b}^{*}\right)$.

All gloss properties are mainly influenced by the number of cycles (Cycle), while the effect of mold temperature is only noticed for R20. Gloss is not significantly affected by injection rate within the domain of experiments $\left[10-40 \mathrm{~cm}^{3} . \mathrm{s}^{-1}\right]$.

Colorimetric response $\left(\mathrm{L}^{*}, \mathrm{a}^{*}\right.$, and $\left.\mathrm{b}^{*}\right)$ shows the same important effect of the number of cycles and injection temperature. Actually, it can be highlighted that this increase is more marked for $\mathrm{L}^{*}$ than both $\mathrm{a}^{*}$ and $\mathrm{b}^{*}$ when both factors come from a minimal level to a maximal level. Nevertheless, the effect of molding temperature and injection rate on color is not significant.

Surface Topography. The appearance properties such as gloss and lightness are classically related to surface roughness. The differences in optical and appearance properties between samples were presumed to arise from the variation in the surface topography according to literature [18, 19, 22].

AFM measurements show mold-scratches on the surface and a good replication of the surface with very small roughness (Table 4).

The probability density functions of slopes (pdf) obtained from the AFM micrographs are presented in Fig. 3.Increasingthe injection rate from $10 \mathrm{~cm}^{3} \cdot \mathrm{s}^{-1}$ to $40 \mathrm{~cm}^{3} \cdot \mathrm{s}^{-1}$ (Fig. 3a) increases slopes, chang-ing surface roughness. The variations are very small and do not affect gloss properties (Table 4). By changing the injection temperature (PPN27 and PPN44), the probability density functions of slopes pdf (Fig. 3b) and R20decrease with the increase in material temperature (Table 4). For PPN7 (cycle 0) and PPN39 (cycle 4) injected with the same parameters but for different cycles, no roughness is detected by AFM, while gloss values are modified specially for R85.

The study of the surface roughness of polypropylene injected samples does not give clear descriptions about the changes in shine for the different samples. In an attempt to find answers to this question, we will look inside the material in the area of skin.

The proposed method is to use the optical microscope observations and analyze statistical characteristic images at different depths in the sample.

\section{LOCAL OPTICAL PROPERTIES IN THE SKIN LAYER OF INJECTED PARTS: EFFECT OF RECYCLING AND INJECTION PARAMETERS}

\section{Objective and Experimental Method}

A first method is based on a basic optical concept. When light encounters a surface, it can be either reflected away from the surface or refracted through the surface to the material beneath. Once in the material, the light can be transmitted, absorbed, or diffused (or some combination) by the material. The amount of diffuse transmission or reflection that occurs when light moves through one material to strike 
another material depends on the difference in refractive index between the two materials and the size and shape of the particles in the diffusing material compared to the wavelength of the light. By using Descartes-Snell and Fresnel equations in the case of polypropylene, we found that light refraction leads up to $95 \%$ transmission. This intensity may be absorbed (pigments with color, specific wavelengths), diffused with a polar diagram depending on size, contact of surfaces (pigment/polymer), and organization of polymer (spherulites, crystalline). In this study, we are interested in the light coming back to the observer to try to explain the results of gloss and color measurements. The proposed method is the measurement of backscattered light by focusing on small location with high in-plane resolution and in different layers from the surface.

\section{Results: The Backscattered Intensity Increases with the Thickness and} Reaches a Maximum Level

Figure 4 shows the changes of skewness and kurtosis versus depth (distance from sample skin) in the samples. For all studied samples, we can notice the existence of peaks of skewness and kurtosis at about the same range of depth ( $30 \mu \mathrm{m}$ relative to the sample surface). These maxima can be related to the material morphology in the skin area. By comparing the skewness and kurtosis plots of PPN1 and PPN10 (Fig. 4a and b); we notice that the values of Skewness and Kurtosis are higher for PPN10 with the highest mold temperature injection. For PPN5 and PPN10 (Figs. 4c and d), the skewness and kurtosis values are higher for the highest value of the injection rate
(PPN5) and finally by comparing PPN27 and PPN44 (Fig. 4e and f) we observe also that the highest skewness and kurtosis are obtained in the case of the highest injection temperature (PPN27). Therefore, the analysis of distribution parameters (skewness, kurtosis) highlights a thickness range where a deviation is observed $(30 \mu \mathrm{m})$. This corresponds to a high intensity tail attributed to the contribution of large pigments. These findings indicate an important relationship between the injection parameters, the morphology in the skin area and the optical response of the samples. To better understand this relationship and the effect of microstructure on the appearance properties of injected polypropylene, we will dedicate the following part to the samples morphology study in the skin area.

The direct way to study the internal organization inside the thickness is the observation of a thin cut obtained along a plane including the thickness and the flow direction. The observation under light polarization under transmission with high magnification reveals the crystalline phase, the size and the shape of spherulites.

In this section, we focus on some representative samples to understand the effect of injection parameters (Temperature of material $\left(\mathrm{T}_{\text {mat }}\right)$, temperature of mold $\left(\mathrm{T}_{\text {mold }}\right)$, Injection rate $\left(\mathrm{Inj}_{\mathrm{rate}}\right)$, cycle) on the morphology evolution and the relationship with the appearance properties of the samples. Thin slices ( $5 \mu \mathrm{m}$ of thickness), cut from injected samples near the surface, were analyzed by polarized light optical microscopy.

Figures 5 and 6 show micrographs obtained from polarized light optical microscopy for some injected polypropylene samples. The increase in spherulites diameters with the increase in mold
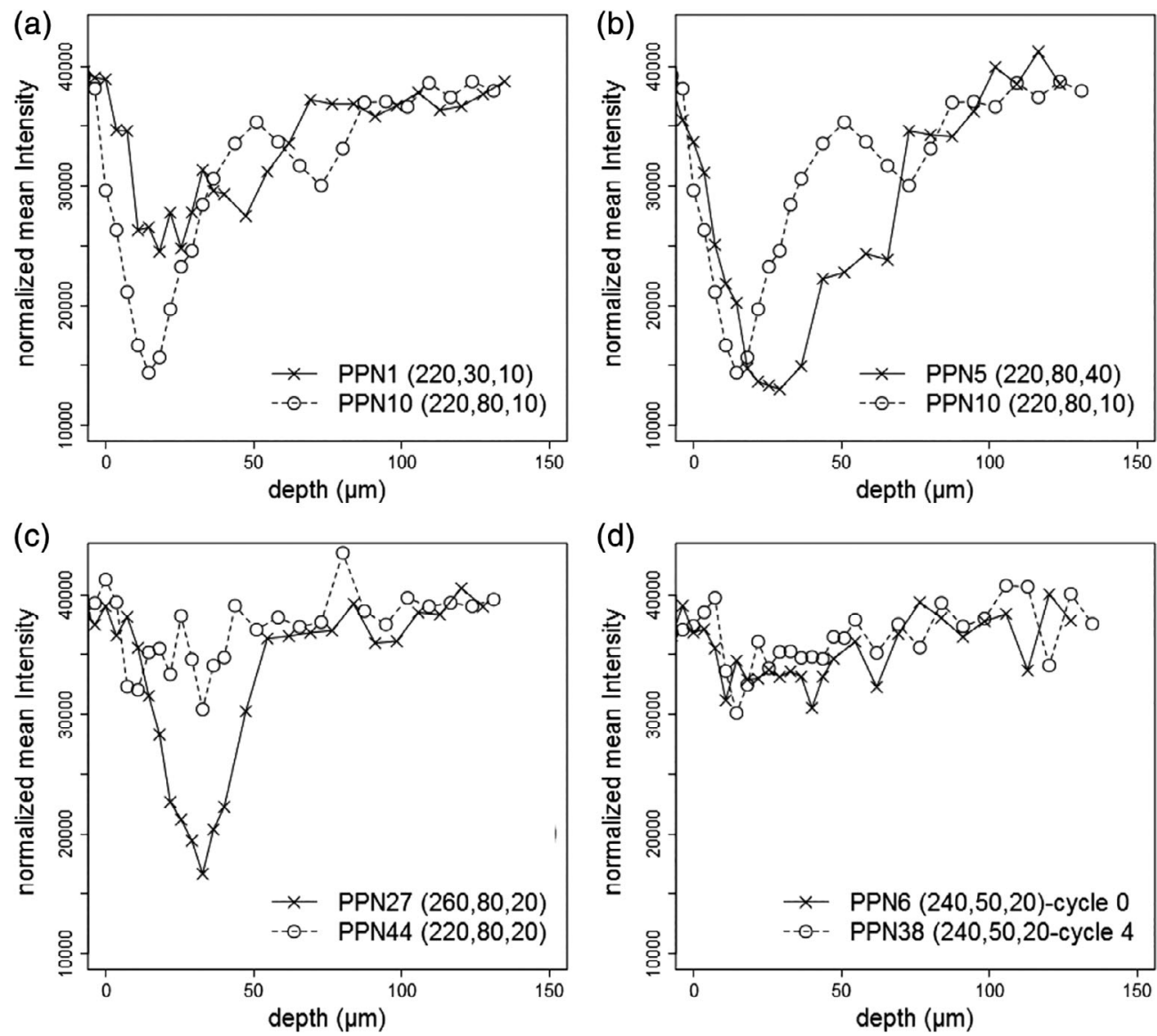

FIG. 8. Mean intensity profiles collected from microscopic images taken at different depths under sample skin after incident intensity normalization. Same samples and layout as FIG. 7. 
temperature is clearly seen in Figs. 5a and 6b. This is also shown by FIG. 7a that demonstrates the variation of spherulites diameters with the distance from the sample skin, PPN10 having the largest spherulites.

This increase in spherulite dimensions is accompanied by an increase in the intensity of light (Fig. 8a). For PPN5 and PPN10 and by increasing the rate of injection from 10 to $40 \mathrm{~cm}^{3} / \mathrm{s}$ (Figs. $5 \mathrm{~b}$ and $6 \mathrm{c}$ ), the dimensions of spherulites do not change a lot but more spherulites of $\beta$ phase are seen at higher injection rate. The intensity of the light does not change as well (Fig. 8b). The effect of injection temperature on spherulite dimensions is shown in Figs. 6a and b and FIG. 7c. The highest dimensions of spherulites are obtained for the PPN27 with the highest injection temperature. This increase in dimension comes with an increase in the intensity of light (Fig. 8c). The recycling has the same effect as the injection temperature by comparing the PPN6 (cycle 0) and PPN38 (cycle4) (Figs. 6c and d, FIG. 7d, and 8d).

The average results of gloss and colorimetry were shown in Table 3. By comparing these results to the curves of FIG. 7, we notice that PPN27, with the highest spherulite dimensions among all samples and with a trans-crystalline zone near the sample surface, also has the most different gloss and color coordinates. For this sample, we have the lowest R20 value together with the highest $R 85, L^{*}, a^{*}$, and $b^{*}$. In general, the results of Table 3 reveal that the effect of spherulite dimensions correlates with gloss and color variations. With increasing spherulite size, R20 decreases while R85 and L* increases (PPN1, PPN10), (PPN27, PPN44), (PPN6, PPN38). The changes in chromaticity are observed especially as an effect of the recycling.

A gradient of spherulite size is observed along depth. The diameter of spherulites depends on processing parameters and is explained by mechanism of nucleation and growth of spherulites. The diameter evolution up to the surface is consistent with the visible spherulites on the surface by AFM and SEM (Figs. 9 and Fig. 10). A part of the roughness results from the crystalline organization. Roughness increases with the increase in the injection temperature (Figs. 9c and d) and decreases with the increase in the injection rate (Figs. 9a and b). The surface morphology of the samples was also investigated by SEM (Fig. 10). By examining the micrographs, we can observe a microroughness that is relatively pronounced and depending on injection parameters. Roughness parameters are coherent with those detected with AFM measurements and confirm the previous discussions.

Microscopic observation with natural light reveals the pigments. No significant heterogeneity of distribution of pigments is observed along the depth. The evolution of gloss and L* follows the size of the spherulites. The morphology of polymer seems to be a key point to explain the optical properties of injected parts.
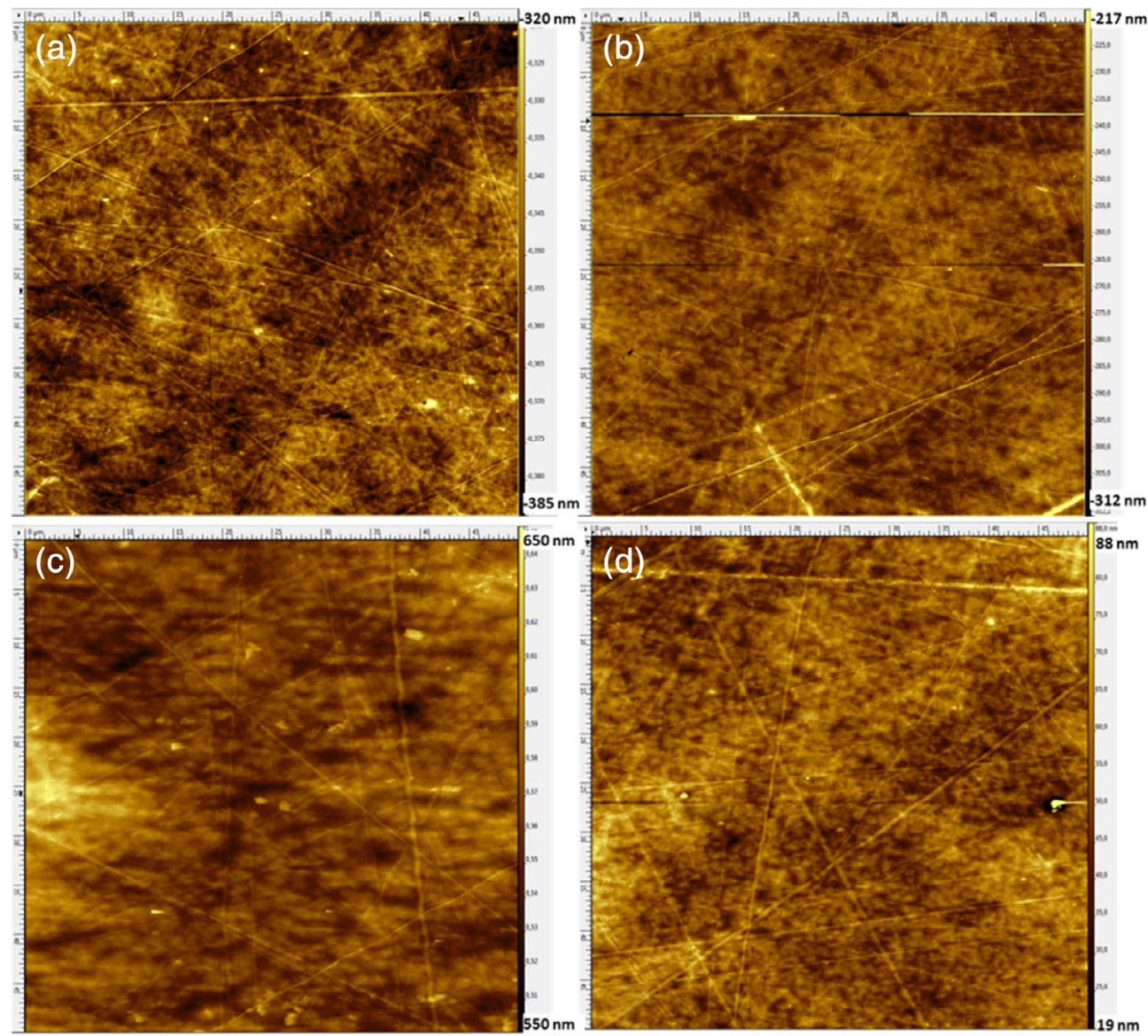

FIG. 9. AFM measurements pictures of PP surfaces $25 \mu \mathrm{m} \mathrm{X} 25 \mu \mathrm{m}$ : (a) PPN5 $\left(T_{\text {mat }}=220^{\circ} \mathrm{C}, T_{\text {mold }}=80^{\circ} \mathrm{C}\right.$, Inj $\left._{\text {rate }}=40 \mathrm{~cm}^{3} / \mathrm{s}\right)$, (b) PPN10 $\left(T_{\text {mat }}=220^{\circ} \mathrm{C}, T_{\text {mold }}=80^{\circ} \mathrm{C}\right.$, Inj $\left._{\text {rate }}=10 \mathrm{~cm}^{3} / \mathrm{s}\right)$, (c) PPN27 $\left(T_{\text {mat }}=260^{\circ} \mathrm{C}, T_{\text {mold }}=80^{\circ} \mathrm{C}\right.$, Inj $\left._{\text {rate }}=20 \mathrm{~cm}^{3} / \mathrm{s}\right)$, (d) PPN44 $\left(T_{\text {mat }}=220^{\circ} \mathrm{C}, T_{\text {mold }}=80^{\circ} \mathrm{C}\right.$, Inj rate $\left.=20 \mathrm{~cm}^{3} / \mathrm{s}\right)$. [Color figure can be viewed at wileyonlinelibrary.com] 

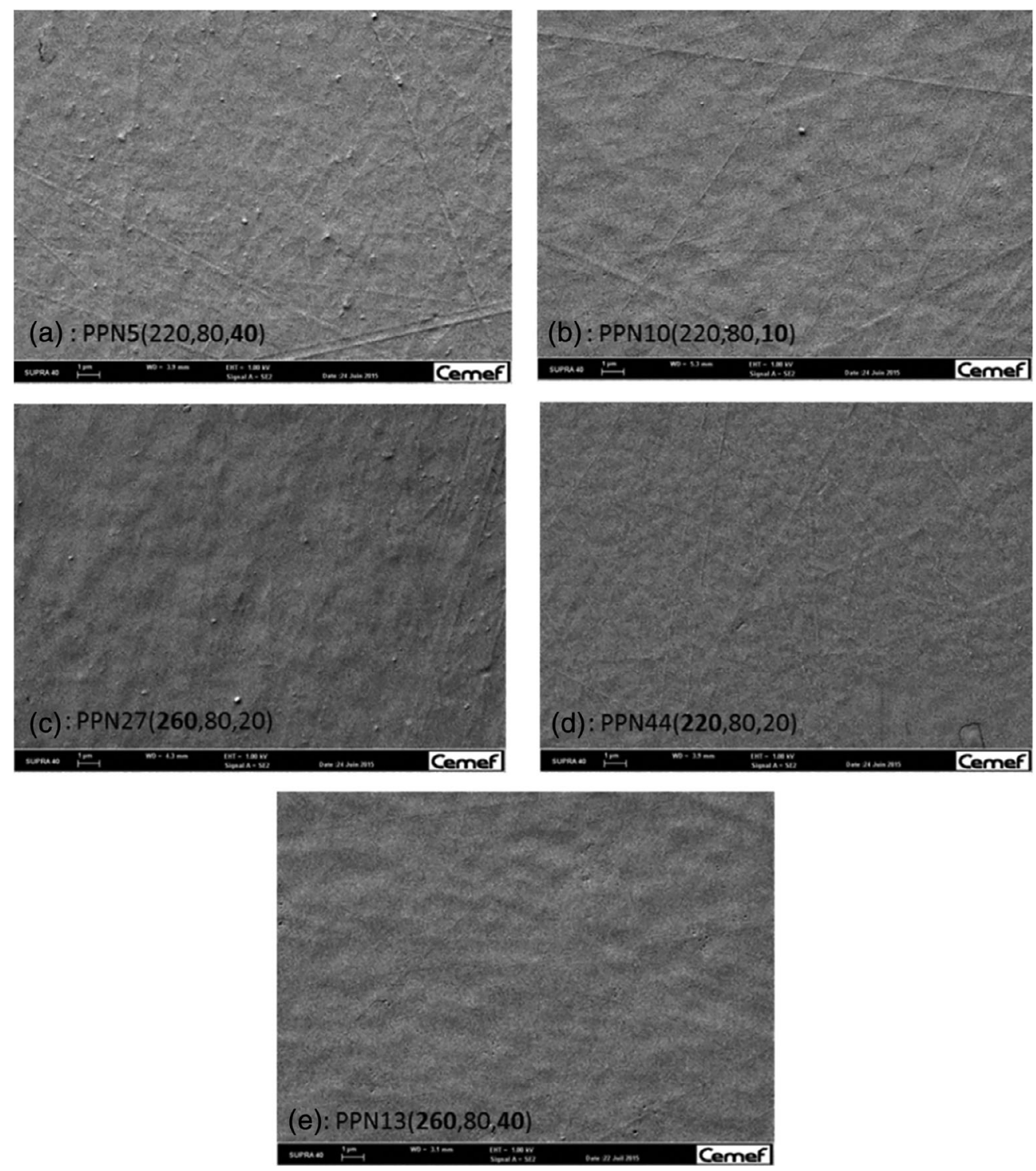

FIG. 10. SEM pictures (X2500) of PP surfaces: (a) PPN5 $\left(T_{\text {mat }}=220^{\circ} \mathrm{C}, T_{\text {mold }}=80^{\circ} \mathrm{C}\right.$, Inj $\left._{\text {rate }}=40 \mathrm{~cm}^{3} / \mathrm{s}\right)$, (b) PPN10 $\left(T_{\text {mat }}=220^{\circ} \mathrm{C}, T_{\text {mold }}=80^{\circ} \mathrm{C}\right.$, Inj $\left._{\text {rate }}=10 \mathrm{~cm}^{3} / \mathrm{s}\right)$, (c) PPN27 $\left(T_{\text {mat }}=260^{\circ} \mathrm{C}, T_{\text {mold }}=80^{\circ} \mathrm{C}\right.$, Inj $\left._{\text {rate }}=20 \mathrm{~cm}^{3} / \mathrm{s}\right),($ d) PPN44 $\left(T_{\text {mat }}=220^{\circ} \mathrm{C}, T_{\text {mold }}=80^{\circ} \mathrm{C}, \operatorname{Inj}_{\text {rate }}=20 \mathrm{~cm}^{3} / \mathrm{s}\right)$, (e) PPN13 $\left(T_{\text {mat }}=260^{\circ} \mathrm{C}, T_{\text {mold }}=80^{\circ} \mathrm{C}\right.$, Inj $\left._{\text {rate }}=40 \mathrm{~cm}^{3} / \mathrm{s}\right)$.

Which is the morphological origin of this change of optical properties? The link between morphology and backscattering requires optical modeling to expect an answer.

\section{MODELING ATTEMPT AND DISCUSSION}

The scattered intensity from an assembly of spherulites is a function of the radius and the number of the spherulites, the polarizabilities along the radial and tangential directions of the spherulites and that of the matrix [38].

Although several models are able to predict small angle light diffusion under transmission, only one seems to be able to predict backscattering (Mie). For spherical objects like spherulites, the model depends on diameter, variation of refractive index and concentration.

Modeling was applied on the geometry of samples including refraction (Descartes, Fresnel) and Mie diffusion. The diffusion is very weak for the spherulites of the size that was measured.
Predicted intensity variations are not consistent with the variations obtained from gloss, lightness and imaging measurements. The spherulite size is too large to explain this backscattering.

A large backscattered intensity requires optical heterogeneities with fluctuations of refractive index larger than 0.001 units and small size (few tenth of nanometer) of the diffusion objects. No model seems to be able to predict this backscattering. The stacking of crystalline lamellae with amorphous phase inside spherulites is a possible candidate to explain this scattering. The thickness of the crystalline lamellae is in the range of $8-15 \mathrm{~nm}$ and the difference of refractive index between crystal and amorphous phase is larger than 0.005 , as an effect of density difference.

The size of spherulites is an indicator of the crystallization condition (temperature, flow). A decrease of crystallization temperature (higher cooling) induces a higher nucleation density, then a decrease of the spherulite size. At the same time, it induces a decrease of the lamellae thickness, and that of the crystallinity. It 
also induces a modification of the mechanism of incorporation of molecular segments inside the crystals and the amorphous phase (growth regime III Hoffman-Lauritzen) [39, 40]. It changes the chain connectivity between the crystal and amorphous layers. A decrease of the crystallization temperature should induce a lesser variation of refractive index, and thus lower diffusion. The measurement of the lamellar thickness as a function of the location inside the thickness is a very difficult task, but it is not within the scope of the present paper. The connectivity between amorphous and crystal is deduced from a molecular model of crystallization kinetics. It predicts the kinetics very precisely but the direct observation of this connection has not been conducted in the literature and is highly speculative. It is a new proposal to explain the measured optical properties (gloss color). The increase of the number of cycles and the material temperature induces the decrease of the molar mass of the polymer [41]. Then, this decrease affects the nucleation process of crystallization. In fact, the mechanisms of crystallization are related to the molecular weight distribution in different ways. Hence, an increase of both crystallization and nucleation rates was observed with the decrease of the molecular weight $[42,43]$. In our case, the number of cycles and the materials temperature induced the highest modifications of the optical properties. These modifications can be associated with the variations of the crystallization.

\section{CONCLUSIONS}

The variations of properties due to multiple recycling are in the same range that is observed by changing processing parameters. The roughness is not able to explain the variation of the optical properties for these variations of conditions. The optical properties of the skin layer of the injected parts are connected with the observed gloss and color variations. The pigments are insufficient to explain these changes. A change of spherulite dimension is associated with optical changes. It is an indicator of a change in the internal semi-crystalline organization in the sample layer that seems to be the key parameter to explain the change in gloss and $\mathrm{L}^{*}$. The optical properties depend not only on the surface of samples, but also on the organization in layer. Moreover, the optical properties of the recycled parts can be maintained during numerous internal recycling.

\section{REFERENCES}

1. N.S. Allen, S.J. Hardy, A.F. Jacobine, D.M. Glaser, B. Yang, D. Wolf, F. Catalina, S. Navaratnam, and B.J. Parsons, J. Appl. Poly Sci, 42, 1451 (1991).

2. Z. Baccouch, S. Mbarek, and M. Jaziri, Polym. Bulletin, 74, 839 (2017).

3. A. Menyhárd, M. Gahleitner, J. Varga, K. Bernreitner, P. Jääskeläinen, H. Oysd, and B. Pukánszky, Eur. Polym. J., 45, 3138 (2009).

4. F. Vilaplana and S. Karlsson, Macromol. Mater. Eng., 293, 274 (2008).

5. M.A. Sukhadia, D.C. Rohlfing, M.B. Johnson, and G.L. Wilkes, J. Appl. Poly Sci, 85, 2396 (2002).

6. I. Ariño, U. Kleist, L. Mattsson, and M. Rigdahl, Polym. Eng. Sci., 45(10), 1343 (2005).

7. R. Kaneda, T. Takahashi, M. Takiguchi, M. Hijikata, and H. Ito, Polym. Eng. Sci., 58, 632 (2017).
8. Z. Ahmad, K.D. Kumar, and M. Saroop, Polym. Eng. Sci., 50, 331 (2010).

9. M. Yoshii, H. Kuramoto, and T. Kawana, Polym. Eng. Sci., 36, 819 (1996).

10. L. Tredoux, I. Satoh, and Y. Kurosaki, Polym. Eng. Sci., 39, 2233 (1999).

11. L. Xie and G. Ziegmann, Microsyst. Technol., 14, 809 (2008).

12. S. Fellahi, A. Meddad, B. Fisa, and B.D. Favis, Adv. Polym. Technol, 14, 169 (1995).

13. J. Lee and L.S. Turng, Polym. Eng. Sci., 50, 1281 (2010).

14. S.C. Chen, Y.W. Lin, R.D. Chien, and H.M. Li, Adv. Polym. Technol, 27, 224 (2008).

15. J.D. Yoon, S.K. Hong, J.H. Kim, and S.W. Cha, Cellular Polym., 23, 39 (2004).

16. S.J. Liu and J.H. Chang, Polymer Composite, 21, 322 (2004). https://doi.org/10.1002/pc.10189.

17. J.J. Lee, L.S. Turng, E. Dougherty, and P. Gorton, Polymer, 52, 1436 (2011).

18. F. Pisciotti, A. Boldizar, M. Rigdahl, and I. Arino, Polym. Eng. Sci., 45, 1557 (2005).

19. M.J. Oliveira, A.M. Brito, M.C. Costa, and M.F. Costa, Polym. Eng. Sci, 46, 1394 (2006).

20. U.A. Theilade and H.N. Hansen, Int. J. Adv. Manuf. Technol, 33, 157 (2007).

21. B. Sha, S. Dimov, C. Griffiths, and M.S. Packianather, J. Mater Process Technol., 284, 183 (2007).

22. K. Watanabe, T. Suzuki, T.T. Masubuchi, J. Takimoto, and K. Koyama, Polymer, 44, 5843 (2003).

23. M. Dong, Z.X. Guo, Z.Q. Su, and J. Yu, J. Polym. Sci. Pt BPolym. Phys., 46, 1183 (2008).

24. R. Zheng, P. Kennedy, N. Phan-Thien, and X.-J. Fan, J. NonNewton Fluid Mech., 84, 159 (1999).

25. J.C. Viana and A.M. Cunha, $O$ Molde, 55, 18 (2002).

26. E. Dawkins, P. Engelmann, K. Horton, and M. Monfore, J. Inj. Mold. Technol., 1, 1 (1998).

27. B. Pukánszky, I. Mudra, and P. Staniek, J. Vinyl Additive Technol., 3, 53 (1997).

28. J. Bergstrom, F. Thuvander, P. Devos, and C. Boher, Wear, 251, 1511 (2001).

29. R. Silvennoinnen, K. Myller, K. Peiponen, J. Salmi, and E. J. Pääkkönen, in International Trends in Optics and Photonics: ICO IV, T. Asakura, Ed., Springer, Heidelberg, Germany, 282 (1999).

30. L. Balzano, S. Rastogi, and G.W.M. Peters, Macromolecules, 41, 399 (2008).

31. D.J. Withehouse, D.K. Bowen, V.C. Venkatesh, P. Lonardo, and C.A. Brown, Cirp Annals., 43, 541 (1994).

32. D. Alcazar, J.R. Ruan, A. Thierry, A. Kawaguchi, and B. Lotz, Macromolecules, 39, 1008 (2006).

33. E.N. Dalal and K.M. Natale-Hoffman, Color Res. Appl., 24, 369 (1999).

34. I. Arino, U. Kleist, and M. Rigdahl, Polym. Eng. Sci., 45(5), 733 (2005).

35. L. Wang, T. Huang, M.R. Kamal, A.D. Rey, and J. Teh, Polym. Eng. Sci., 40, 747 (2000).

36. X. Guo, A.I. Isayev, and L. Guo, Polym. Eng. Sci., 39, 2096 (1999).

37. R. Pantani, I. Coccorullo, V. Speranza, and G. Titomanlio, Prog. Polym. Sci., 30, 1185 (2005). 
38. R.S. Stein and M.B. Rhode, J. Appl. Phys., 31, 1873 (1960).

39. J.D. Hoffman and J.I. Lauritzen Jr., J. Res. Nat. Bureau Stand., 65A, 297 (1961).

40. J.I. Lauritzen Jr. and J.D. Hoffman, J. Appl. Phys., 44, 4340 (1973).
41. M. Gahleitner, K. Bernreitner, and W. Neil, Polym. Test., 14, 173 (1995).

42. A. Krumme, A. Lehtinen, and A. Viikna, Eur. Polym. J., 40, 359 (2004).

43. A. Krumme, A. Lehtinen, and A. Viikna, Eur. Polym. J., 40, 371 (2004). 